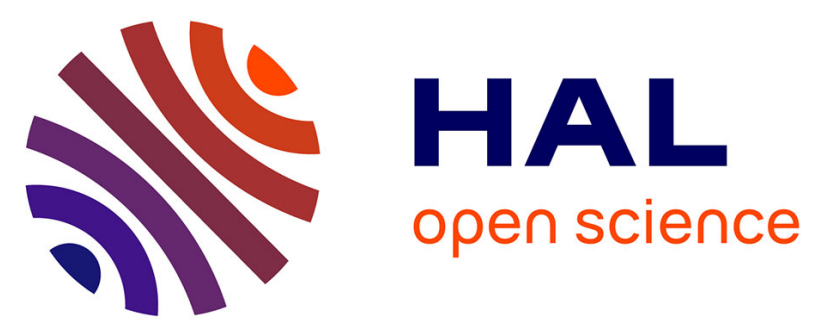

\title{
Microstructural and Mechanical Characterization of the Yb: YAG Laser Welding of High-Pressure Die-Casting Mg-Al-Mn Magnesium Alloy
}

Seddik Ouallam, Jean-Eric Masse, Patrice Peyre, Lamine Djeghlal, Fabrice Guittonneau, Zoheir Boutaghou, Liamine Kaba

\section{To cite this version:}

Seddik Ouallam, Jean-Eric Masse, Patrice Peyre, Lamine Djeghlal, Fabrice Guittonneau, et al.. Microstructural and Mechanical Characterization of the Yb: YAG Laser Welding of High-Pressure DieCasting Mg-Al-Mn Magnesium Alloy. International Journal of Engineering Research in Africa , 2020, 51, pp.95-109. 10.4028/www.scientific.net/JERA.51.95 . hal-03269858

\section{HAL Id: hal-03269858 https://hal.science/hal-03269858}

Submitted on 24 Jun 2021

HAL is a multi-disciplinary open access archive for the deposit and dissemination of scientific research documents, whether they are published or not. The documents may come from teaching and research institutions in France or abroad, or from public or private research centers.
L'archive ouverte pluridisciplinaire HAL, est destinée au dépôt et à la diffusion de documents scientifiques de niveau recherche, publiés ou non, émanant des établissements d'enseignement et de recherche français ou étrangers, des laboratoires publics ou privés. 


\title{
Microstructural and Mechanical Characterization of the Yb: YAG Laser Welding of High-Pressure Die-Casting Mg-Al-Mn Magnesium Alloy
}

\author{
Seddik OUALLAM ${ }^{1,2,3, a^{*}}$, J.E. Masse ${ }^{3, b}$, P. Peyre ${ }^{4, c}$, M.L.Djeghlal2,d $^{2,}$ F. \\ Guittonneau ${ }^{3, \mathrm{e}}$, Z.Boutaghou ${ }^{1, \mathrm{f}}$ and L.Kaba1'g, \\ ${ }^{1}$ Research Center in Industrial Technologies, P.O. Box 64, Chéraga, 16014 Algiers, Algeria. \\ ${ }^{2}$ Department of Metallurgy, Polytechnic National School (ENP), 10 Avenue Hassen Badi, P.O. Box 182, \\ El Harrach, 16200 Algiers, Algeria. \\ ${ }^{3}$ MSMP Laboratory, Arts et Métiers ParisTech, 2 cours des Arts et Métiers, 13100 Aix-en-Provence, \\ France \\ 4PIMM Laboratory, Arts et Métiers ParisTech, 151 boulevard de l'Hôpital, 75013 Paris, France

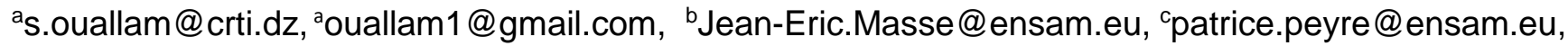 \\ ddmlamine2015@gmail.com, eFabrice.GUITTONNEAU@ensam.eu, ${ }^{\mathrm{f}} \mathrm{z}$. boutaghou@crti.dz , \\ g..kaba@crti.dz.
}

Keywords: AM60 magnesium alloy; laser welding; microstructure; Electron backscattered diffraction technique; X-ray diffraction; mechanical properties

\begin{abstract}
In this work, the Yb:YAG laser beam welding of the magnesium alloy AM60 was studied. A laser power of $2 \mathrm{~kW}$ and a welding speed of $3.5 \mathrm{~m} / \mathrm{min}$ give a different welding quality than that obtained by $\mathrm{CO}_{2}$ laser with the same parameters. The metallurgical characterization, by optical microscopy, showed the formation of four distinct zones : base metal (BM), heat affected zone (HAZ), the partially fusion zone (PFZ) and the fusion zone (FZ), due to the thermal effect produced by the laser welding thermal cycle. Their dimensions are quantified. The microstructural examination using scanning electron microscopy showed the presence of fine dendritic structure in the FZ although the use of electron dispersive spectroscopy analysis confirm that an eutectic $\mathrm{Mg}_{17} \mathrm{Al}_{12}$ phase are surrounded by $\alpha-\mathrm{Mg}$ solid solution in the HAZ. Electron backscattered diffraction technique revealed an important grain refinement in FZ and considerable twining phenomena in HAZ, but no texture. X-ray diffraction technique has been used, full width at half maximum of diffraction peaks is measured; it also confirmed the grain refinement in FZ in comparison to BM and HAZ. Both microhardness and tensile proprieties of the complete weld joint are similar to those of the BM.
\end{abstract}

\section{Introduction}

Low-density metal alloys can be considered the most interesting materials in aeronautics, car and railway industries because they decrease enormously the effects of mass in movement. In this context, magnesium alloys are nowadays very interesting [1]. The latter is chiefly used in several components in the aeronautic domain, in the automobile sector and transport transmission [2].

Most of actual european and world researches are oriented in development of new magnesium alloys in order to improve their mechanical resistance as well as their manufacturing and casting processes. In the last ten years, certain studies in the aeronautical field have concentrated on the treatment of these alloys such as shaping by deformation or by thermal treatment and evaluating their behavior under 
mechanical stresses. However, there is a lack of study in the welding mechanical properties of these materials. In weldability of light alloys such as magnesium, high risk of porosity defect and weld cracking are important and reported in literature. Nowadays, the tungsten inert gas (TIG) [3] and metal inert gas (MIG) [4], hybrid TIG/MIG [5], laser and friction stir welding (FSW) welding techniques [6] are the most used to join magnesium alloys.

Laser welding is developing because, compared to other processes, less heat input is introduced in work pieces with high speed, high penetration and precise execution, resulting in a small heat affected zone (HAZ) and low residual stress and distortion of joints [7]. The weld quality depends on numerous process parameters. The principally influent parameters are beam power, welding speed, focal point position and shielding gas flow.

The weldability of magnesium alloys with laser technologies is today an important field of study.

Several studies had been made to optimize these parameters and to investigate the metallurgical and mechanical consequences of magnesium alloys laser welding [7-8]. The most studied materials are the magnesium-aluminum-zinc alloys series [9-12] and laser welding process used are $\mathrm{CO}_{2}$ and $\mathrm{Nd}$ :YAG laser welding [13-15]. However, limited welding researches are realized for AM60B magnesium-based alloy used in automotive industry. This alloy can be found in car interior applications. The major fields are instrument panels, steering and seat structures.

In addition, in recent years, laser sources have made great strides in terms of power delivery, beam transport and ergonomics. Carbon dioxide and Nd:YAg laser sources tend to be replaced by disc lasers when power requirements allow. Intelligent activation concepts with a high degree of functionality make it possible to integrate these lasers particularly easily and flexibly.

Therefore, in this work, we decided to study the Yb:YAG disc laser beam weldability of AM60 magnesium alloy for industrial applications in the automotive field. Compared to $\mathrm{CO}_{2}$ Laser and Nd:YAG laser, the Yb:YAG present a higher welding efficiency due to the higher absorption degree of short wave light [16], which allows a highest energy efficiency [17], hence to higher power densities [18] and the possibility of using low laser power during welding. As a result, it provides high penetration and a low heat-affected area with high welding speed for a given power when welding with a Yb:YAG laser source.

Two aspects were studied: (i) the first is the control and the understanding of the process, which consisted to choose the welding laser parameters. Only the effect of speed was presented. (ii) the second is the metallurgical and mechanicals characterization, through the study of the effect of phases transformations and changes in microstructures during the laser welding in order to validate the process for industrial applications.

\section{Material and methods}

A cast $3 \mathrm{~mm}$ thick AM60B alloy with chemical composition is given in Table 1, provided by Honsel was used for this investigation. The plates are manufactured by means of a high-pressure die-casting process (HPDC). Fusion and casting are conducted under neutral gas and no heat treatments are applied after casting.

Table 1 Chemical composition of base metal (wt.\%).

\begin{tabular}{|l|l|l|l|l|l|l|}
\hline Elements & $\mathrm{Al}$ & $\mathrm{Mn}$ & $\mathrm{Zn}$ & $\mathrm{Si}$ & $\mathrm{Ni}$ & $\mathrm{Mg}$ \\
\hline Base metal & 5.76 & 0.209 & 0.0320 & 0.0209 & 0.0012 & balance \\
\hline
\end{tabular}

The tests were carried out with a Trumpf $10 \mathrm{~kW}$ continuous diode pumped Yb:YAG laser with a $1.030 \mu \mathrm{m}$ wavelength. This laser is equipped with a $400 \mu \mathrm{m}$ optical fiber diameter which transports the laser beams to the welding head along an optical path to the alloy to be welded (Fig.1). The laser beam, diverging at the output of the optical fiber, is made parallel by the collimating lens and is then focused on the part to be welded by the objective of focusing. The optical materials used are a standard $200 \mathrm{~mm}$ Trumpf collimation lens and $300 \mathrm{~mm}$ Trumpf standard focusing lens. In our operating conditions, the diameter of laser spot is $600 \mu \mathrm{m}$ on the surface of the parts to be welded.

The butt welding was performed without gap to prevent concavity due to air gaps [18] and without filler metal (Fig.2), with constant laser power of $2 \mathrm{~kW}$ and variable welding speeds from $3 \mathrm{~m} / \mathrm{min}$ to $5 \mathrm{~m} / \mathrm{min}$. Using these conditions, keyhole-type welds were produced in plates to be welded due to the 
higher energy density transferred to the material. As the beam advanced, the molten metal filled behind the beam to form the joint. The main parameters of the process (beam power, focal point position and argon flow) are constant. Only the speed changes as shown in Table 2.

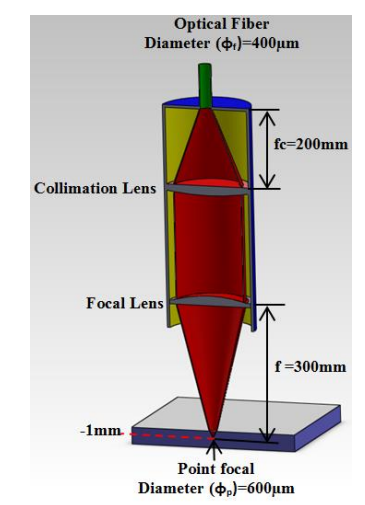

Fig.1: The optical path of the welding head

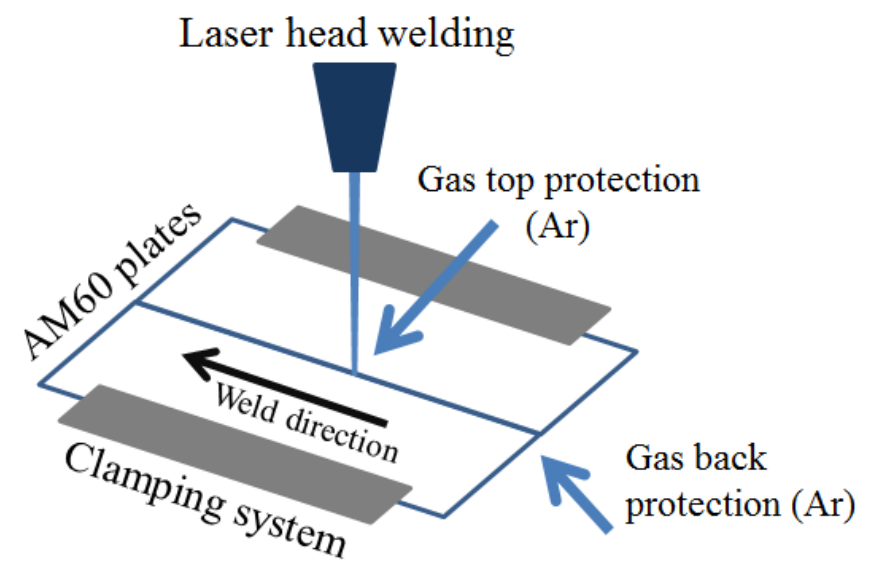

Fig.2: Operating conditions for welding AM60B plates

Table 2: Yb:YAG Welding parameters

\begin{tabular}{|c|c|c|c|c|c|c|}
\hline $\begin{array}{c}\text { Test } \\
\mathrm{N}^{\circ}\end{array}$ & $\begin{array}{c}\text { Focal point } \\
\text { seize }(\mathrm{mm})\end{array}$ & $\begin{array}{c}\text { Focal point } \\
\text { position } \\
(\mathrm{mm})\end{array}$ & $\begin{array}{c}\text { Laser power } \\
\mathrm{P}(\mathrm{W})\end{array}$ & $\begin{array}{c}\text { Welding speed } \\
\mathrm{V}(\mathrm{m} / \mathrm{min})\end{array}$ & $\begin{array}{c}\text { Shielding gas } \\
(\mathrm{L} / \mathrm{min})\end{array}$ & $\begin{array}{c}\text { Heat input } \\
\mathrm{P} / \mathrm{V}(\mathrm{J} / \mathrm{mm})\end{array}$ \\
\hline 1 & 0.6 & -1 & 2000 & 2.5 & 50 & 48.0 \\
\hline 2 & 0.6 & -1 & 2000 & 3.0 & 50 & 40.0 \\
\hline 3 & 0.6 & -1 & 2000 & 3.5 & 50 & 34.3 \\
\hline 4 & 0.6 & -1 & 2000 & 4.0 & 50 & 30.0 \\
\hline 5 & 0.6 & -1 & 2000 & 4.5 & 50 & 26.7 \\
\hline
\end{tabular}

After welding, the weld quality was initially evaluated by visual observation then an X-rays radiographic technique was used to detect internal defects in weld seams. The weld bead retained for the characterization was performed with optimized process parameters: power of $2 \mathrm{KW}$, welding speed of 3.5 $\mathrm{m} / \mathrm{min}$ and a focal point located $1 \mathrm{~mm}$ below the surface of the sample. Water jet cutting is used to collect tensile specimens and metallographic samples for the various observations, as shown in (Fig 3). 


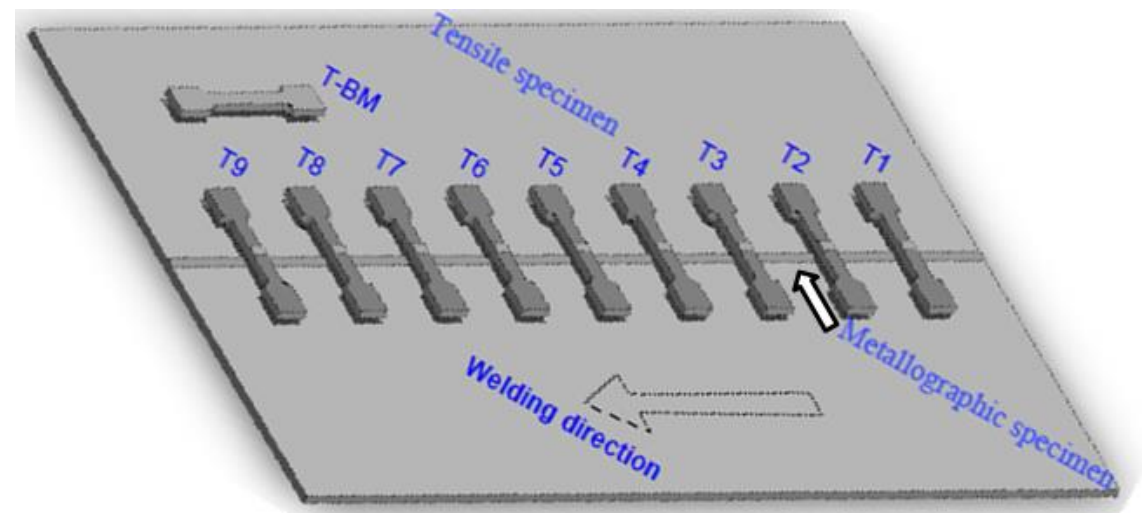

Fig.3: Sampling position of metallography and tensile test specimens

The samples for the optical microscopy (OM) and scanning electron microscopy (SEM) were mechanically polished with an automatic polisher with a rotation of $150 \mathrm{rpm}$ and a pressure of $20 \mathrm{lbf}$ using $\mathrm{SiC}$ paper of 800 to 4000 grit and final polishing was performed using an oil based diamond suspensions of $3 \mu \mathrm{m}$ and $1 \mu \mathrm{m}$ respectively. Between the lasts steps of final polishing, the specimens were rinsed with methanol, dried and immediately etched. After polishing, the samples are etched with acetic glycol etchant (60 ml ethylene glycol, $20 \mathrm{ml}$ acetic acid, $19 \mathrm{ml}$ water, $1 \mathrm{ml} \mathrm{HNO}$ ). This reagent makes it possible to highlight the grain boundaries [19]. Cleaning of the samples in an ultrasonic tank and then ethanol rinsing is always applied before and after chemical attack before observation with OM or SEM. The macrostructure observations were performed using a Leica optical macroscope. Metallurgical characterizations are made using a Leitz Aristomet optical microscope and a SEM JEOL7001F equipped with an Oxford EDS.

For Electron backscatter diffraction (EBSD) characterization, the sample was etched with a solution of $10 \mathrm{ml}$ nitric acid, $30 \mathrm{ml}$ acetic acid, $40 \mathrm{ml}$ water, $120 \mathrm{ml}$ ethanol for $10 \mathrm{~s}$ [20]. This reagent makes it possible to highlight the grain structures. Special attention is given to the EBSD observations where the samples after chemical etching are cleaned in an ultrasound tank and then rinsed, dried and immediately observed to reduce the risk of significant oxidation of the surface to be observed. EBSD analysis, were performed using a Nordlys camera and a HKL CHANNEL5 acquisition and processing system with parameters of $20 \mathrm{kV}$ electron beam and $16 \mathrm{nA}$ current probe.

The phases and precipitates evolutions on the different zones of the weld were determined by X-ray diffraction analysis (XRD). A Bruker D8 Discover XRD was used with $\mathrm{Cu} \mathrm{K} \alpha$ radiation of $0.154 \mathrm{~nm}$, operating at $40 \mathrm{kV}$ power and $40 \mathrm{~mA}$ current and a focal diameter of $0.3 \mathrm{~mm}$. The samples were scanned from $2 \theta=20^{\circ}$ to $90^{\circ}$, with a $2 \mathrm{~s} /$ step count time and $0.015^{\circ}$ step size. The analyzed areas are shown in (Fig.4).
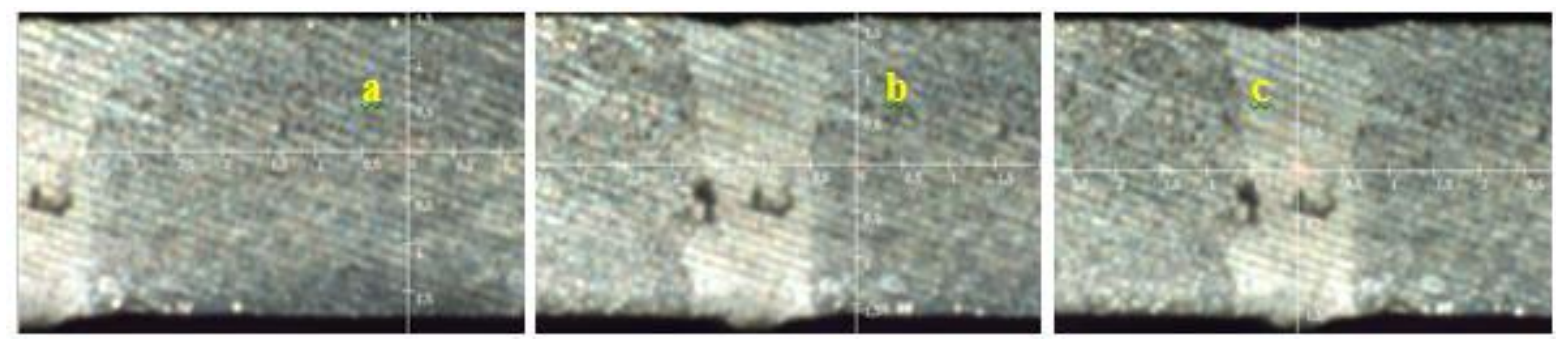

Fig.4: The XRD zones analyzed: (a) BM, (b) HAZ, (c) FZ.

In mechanical characterization, microhardness and tensile test were performed. For Vickers microhardness tests, the samples are prepared in the same way as for optical microscopy, without the final chemical etching. Each indentation is performed under a load of $4.903 \mathrm{~N}$ for 15 seconds. These tests were conducted on a Leica type VMHT machine. The measurements are taken through the weld joint 
according to scans with a $0.5 \mathrm{~mm}$ step as shown in (Fig.5). An average hardness is calculated and an error bar is determined.

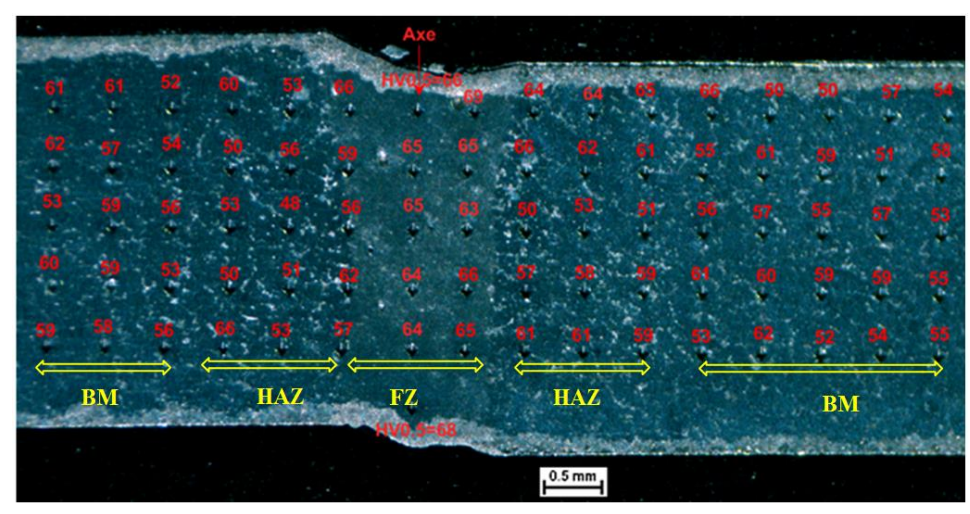

Fig.5: HV0.5 position of scanning test

For tensile strength, tests were performed on base metal samples and welded samples. The laser-welded samples were taken so that the welding axis is in the center of the sample (Fig.3). The shape and dimensions of the tensile test specimens, in accordance with ASTM E8, are shown in (Fig.6). Tensile tests were performed at $5 \mu \mathrm{m} . \mathrm{min}^{-1}$ strain rate using a Kammrath \& Weiss machine with mechanical grips and a $5 \mathrm{kN}$ load cell. Two types of specimens were tested, without and with polishing of laser weld zone to allow a consistent comparison.

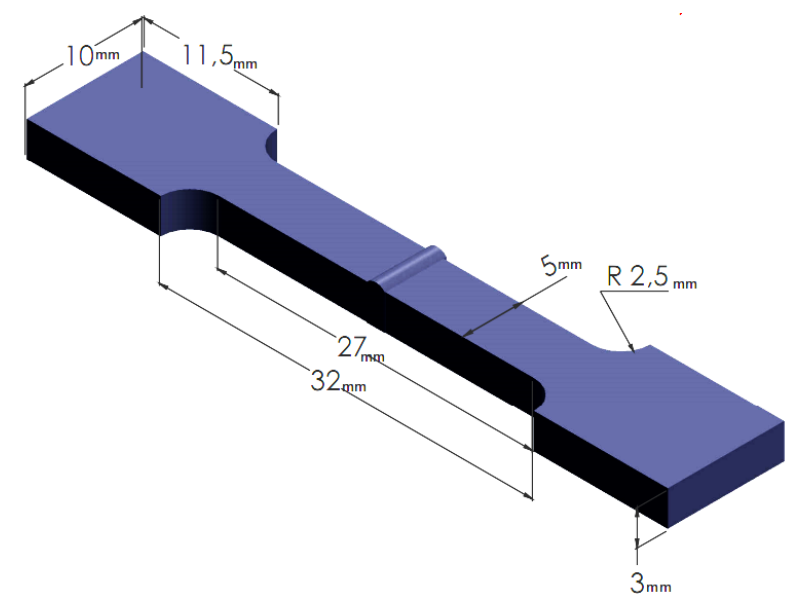

Fig.6: Specimen tensile test dimensions

\section{Results and discussions}

\subsection{Field of operatory weldability:}

It is the set of welding parameters allowing realizing welds satisfying criteria of quality defined by the NFL06-395 standard [21]. Fig.7 shows the effect of the welding parameters applied (Table.2) in order to define the operational weldability domain of the Yb:YAG laser on the AM60B alloy. Thus for speeds ranging from $2.5 \mathrm{~m} / \mathrm{min}$. to $3.5 \mathrm{~m} / \mathrm{min}$, the welds obtained are full penetrating (Fig7a,b,c) and beyond these speeds, the welds lack penetration (Fig7d,e,f,). 


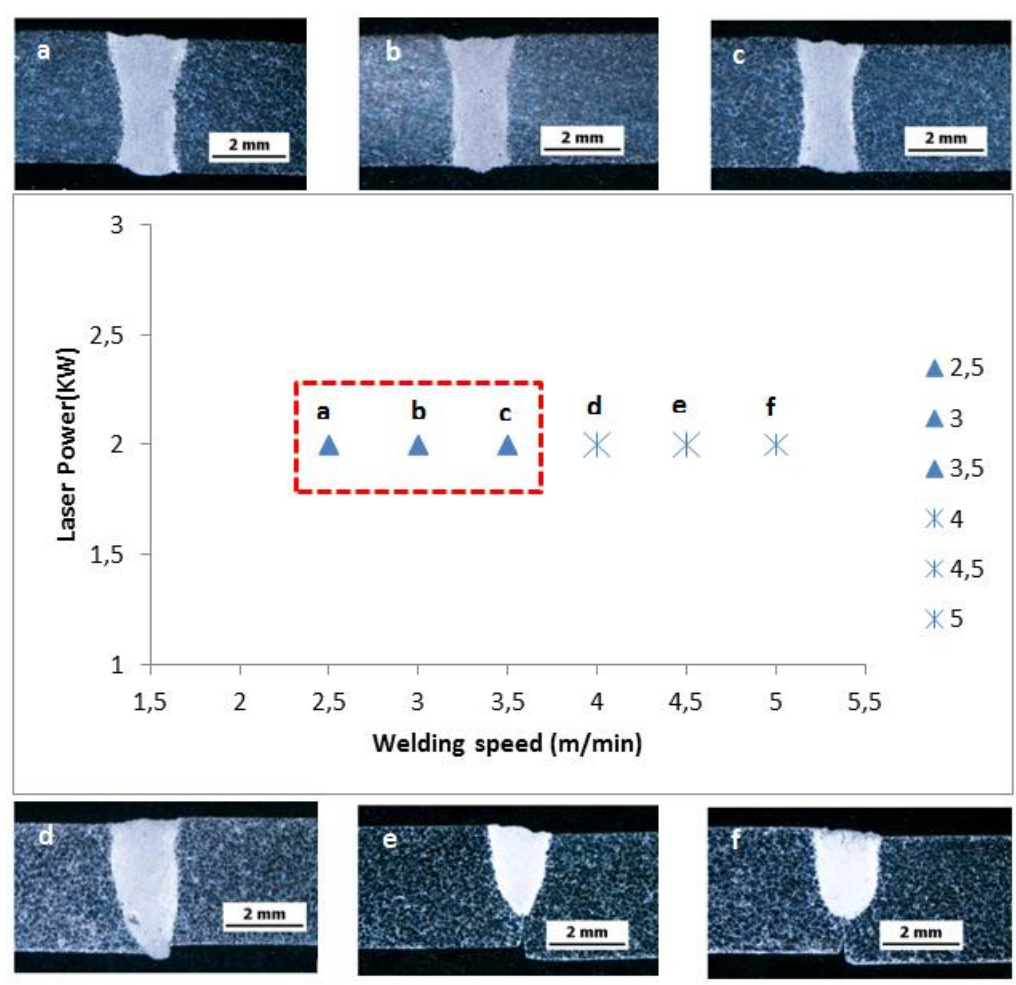

Fig.7: Suitable welding speed range for constant laser beam power

In contrast to Belhadj's work [8], the combination of laser power and welding speed of $2 \mathrm{~kW}$ and 3.5 $\mathrm{m} / \mathrm{min}$ produces a good weld that meets the penetration criterion. This can be explained by the greater absorption of the laser beam by the material due to the short wavelength of the Yb:YAG laser and the greater energy deposition on the surface due to the higher beam concentration [18]. This gives the Yb:YAG process an advantage over $\mathrm{CO}_{2}$ lasers and even Nd:YAG lasers. Fig.8 shows the effect of the welding speed on the bead width and penetration depth. We can note that for welding speed of $2.5 \mathrm{~m} / \mathrm{min}$ to $5 \mathrm{~m} / \mathrm{min}$ the depth/width ratio decrease (Fig.7 and 8). Thus, the increase in speed decreases the depth of penetration and the width of the weld bead. This is due to the decrease of the linear energy that is inversely proportional to the speed for a constant power [22].

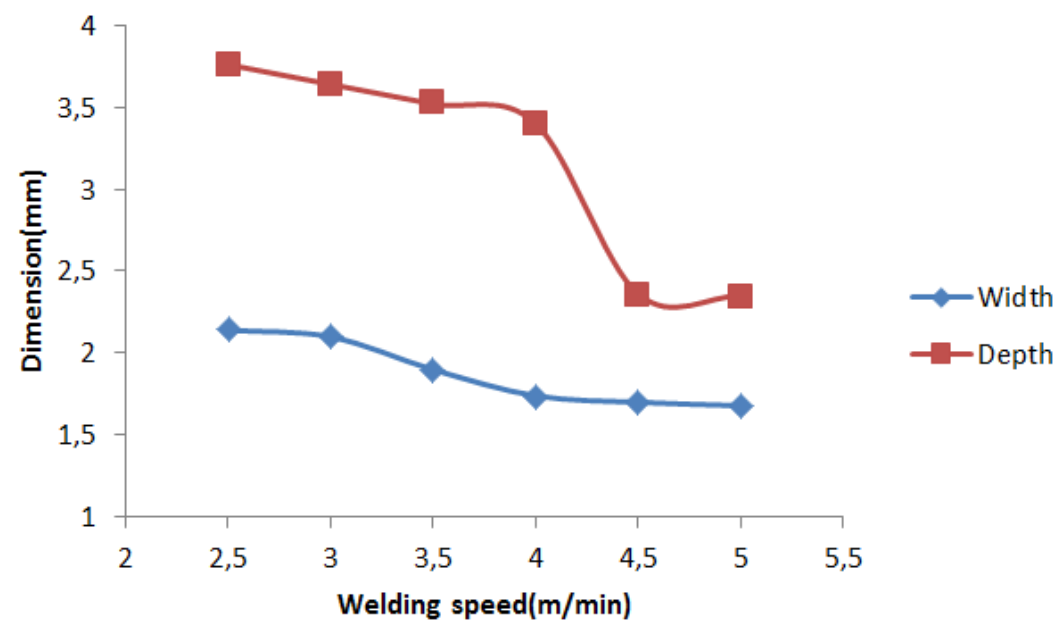

Fig.8: Effect of Yb-YAG Laser welding speed

\subsection{Metallurgical characterization}

For the selected process parameters $(\mathrm{P}=2 \mathrm{KW}$ and $\mathrm{V}=3.5 \mathrm{~m} / \mathrm{min})$ for the metallurgical study, the appearance of the weld seam on the face up and down is given by (Fig.9a,b). The characteristic shape of a laser weld with the trace of cooling isotherms can be observed on the top of the bead (Fig.9a). On the rear 
side, it can be seen that the penetration is not completely uniform (Fig.9b).Note that no cracks were observed in weld seam. Fig.9c represents the macrostructure of the cross-section and shows the existence of three distinct zones defined as BM, HAZ and FZ.
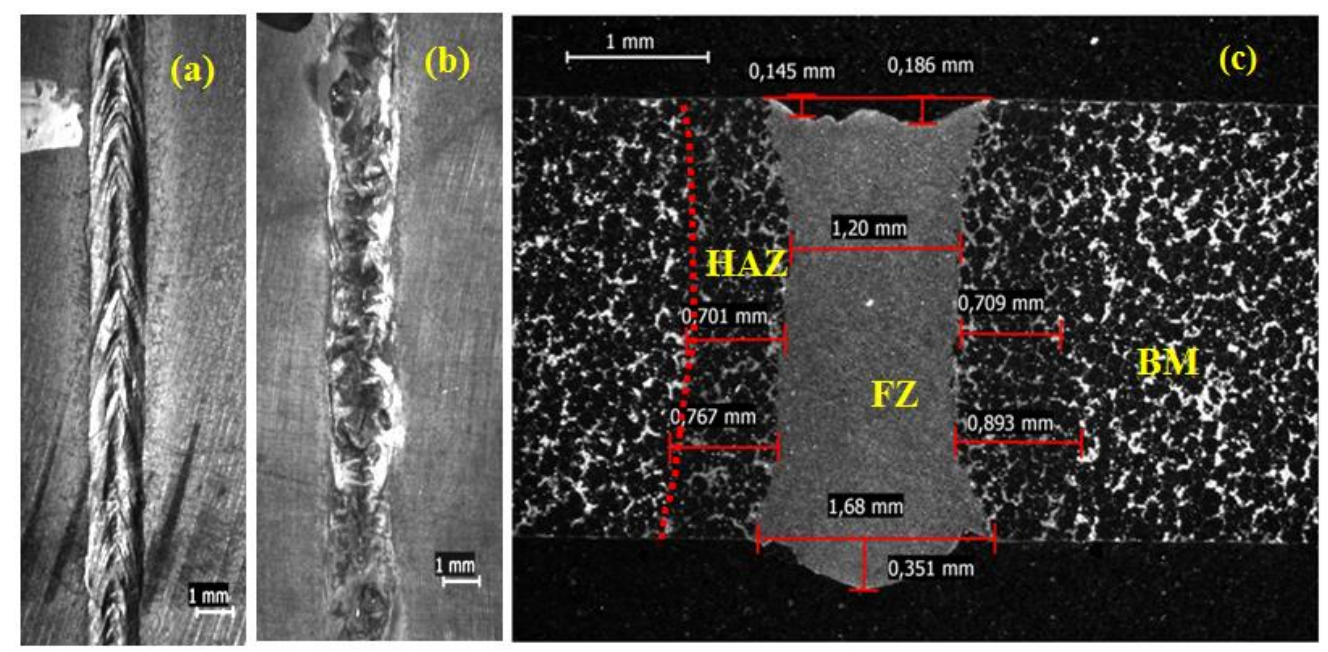

Fig.9: (a) Up face of bead weld, (b) down face of bead weld and (c) Macrography of junction

In Fig.9c, the mean width of the obtained bead is about $1.6 \mathrm{~mm}$. Due to high thermal heat conductivity of magnesium; it was observed that detected HAZ is very small, with about $0.7 \mathrm{~mm}$ in thickness. Microscopically, a fourth zone is observed, which is also a transition zone between HAZ and FZ, where the phase transformation is from the liquid-solid state to the solid state, identified as a partially fusion zone (PFZ). This vulnerable area can lead to liquation cracks [23].

The Fig.10a-c shows the structural evolution of the thermal effect of laser welding Yb:YAG under a linear energy of $34 \mathrm{~J} / \mathrm{mm}$. The yellow circles in Fig.10a and Fig.10b indicate the areas observed by SEM that allows a finer observation of the intergranular areas. The $\mathrm{BM}$ contains $\mathrm{Al}$ as a major alloying element whereas small amounts of $\mathrm{Mn}$ and $\mathrm{Zn}$ are also present. In additions, there are a number of impurity elements like $\mathrm{Fe}, \mathrm{Cu}$ and $\mathrm{Si}$. The initial microstructure is composed of coarse equiaxed $\alpha-\mathrm{Mg}$ grains with $\alpha-\mathrm{Mg}-\mathrm{Mg}_{17} \mathrm{Al}_{12}$ eutectic phase [24-25] located on grain boundary (Fig.10a2). Some of the alloying elements and the impurity elements form intermetallic particles and the most important are those of the form $\mathrm{Al}_{8} \mathrm{Mn}_{5}$ (Fig.10a2 and Fig.10b2) [23-26]. These particles are localized on $\alpha$-Mg matrix and in grains boundaries.

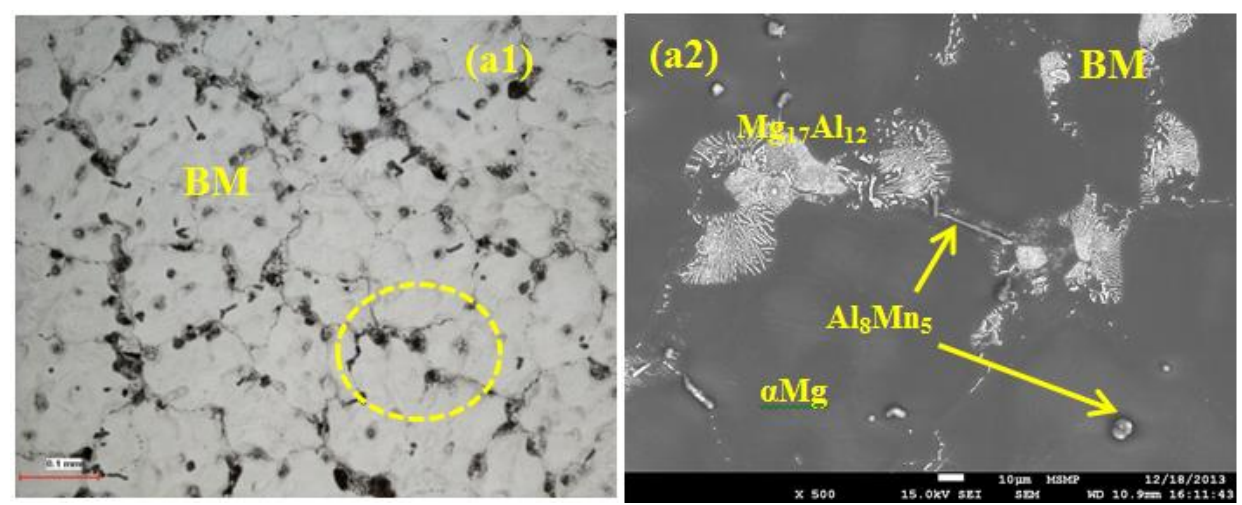

Fig.10a: BM microstructure; (a1) OM, (a2) SEM: eutectic phases $\left(\alpha M g-\mathrm{Mg}_{17} \mathrm{Al}_{12}\right)$ in $\mathrm{BM}$ and $\mathrm{Al}_{8} \mathrm{Mn}_{5}$ precipitates. 

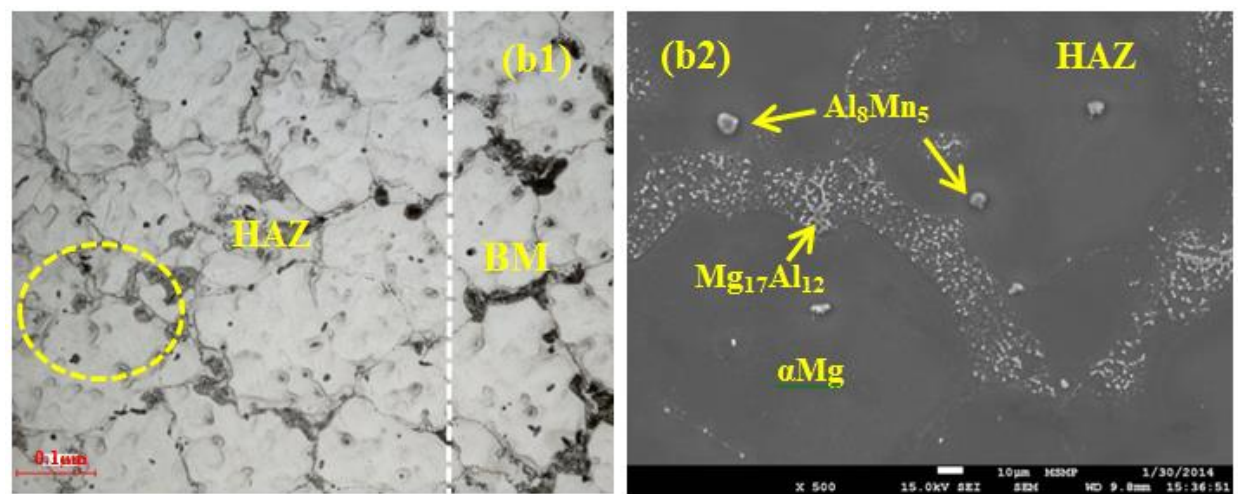

Fig.10b: HAZ Microstructure; (b1) OM, (b2) SEM: phases $\left(\alpha \mathrm{Mg}-\mathrm{Mg}_{17} \mathrm{Al}_{12}\right)$ with island forms and $\mathrm{Al}_{8} \mathrm{Mn}_{5}$ spherical precipitate.
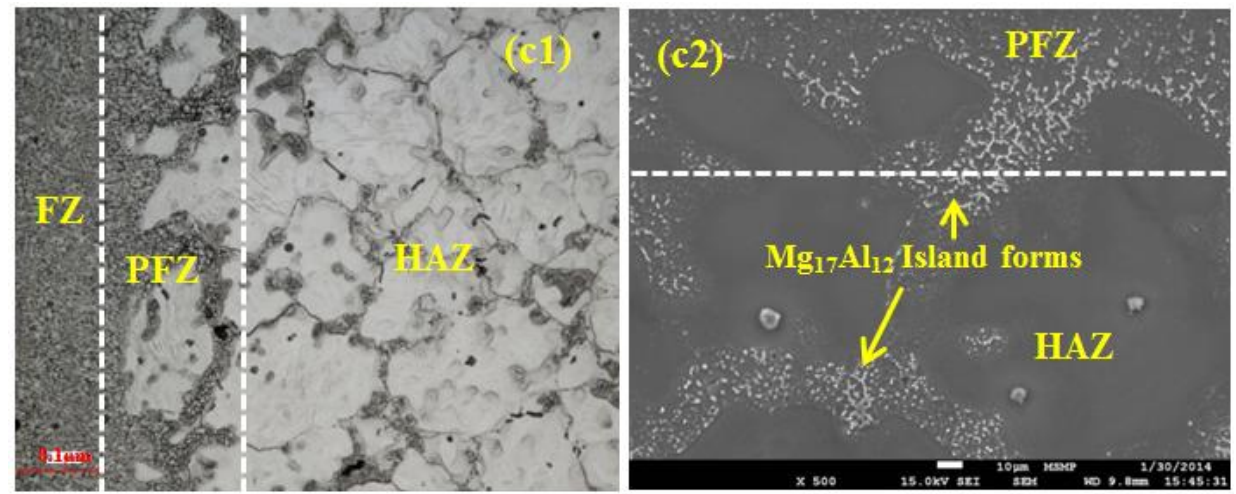

Fig.10c: PFZ Microstructure; (c1) OM, (c2) SEM: phases ( $\left.\alpha \mathrm{Mg}-\mathrm{Mg}_{17} \mathrm{Al}_{12}\right)$ with island forms.
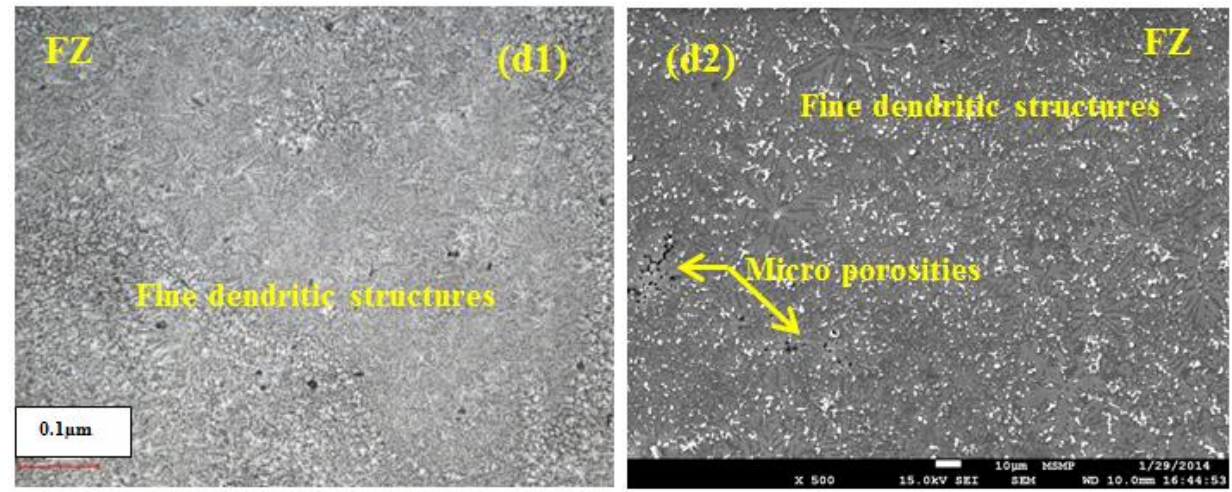

Fig.10d: FZ dendritic microstructures; (d1) OM, (d2) SEM.

Unlike BM, in FZ (Fig.10d), where occurs the phase transformation from the liquid state to the solid state, fine equiaxed dendritic in middle and columnar dendritic near PFZ was observed. These results are characteristics of high solidification thermal gradient due to high energy density produced by Yb:YAG laser beam welding. The island forms [27-28] of the $\mathrm{Mg}_{17} \mathrm{Al}_{12}$ phase (Fig.10c) are always much narrower in the HAZ and FZ and on the BM are located only on the grain boundaries. However, after solidification FZ is characterized by a significant grain refinement. Liu et al. had observed this structure with high solidification rate of as-cast magnesium alloys melded by laser radiation [29].

The application of EBSD technique in laser welds on the AM60B alloy is little known. Fig.(11a) shows the EBSD orientation map, which confirms grain refinement in FZ. Some thermally induced twins appear to be present in many grains in HAZ than in BM. Twinning is an important and well-known deformation mechanism for magnesium alloys [30]. It should be noted that the $\mathrm{Mg}_{17} \mathrm{Al}_{12}$ phase observed above (Fig.10) at the grain boundary on the HAZ and BM could not be diffracted by EBSD. 

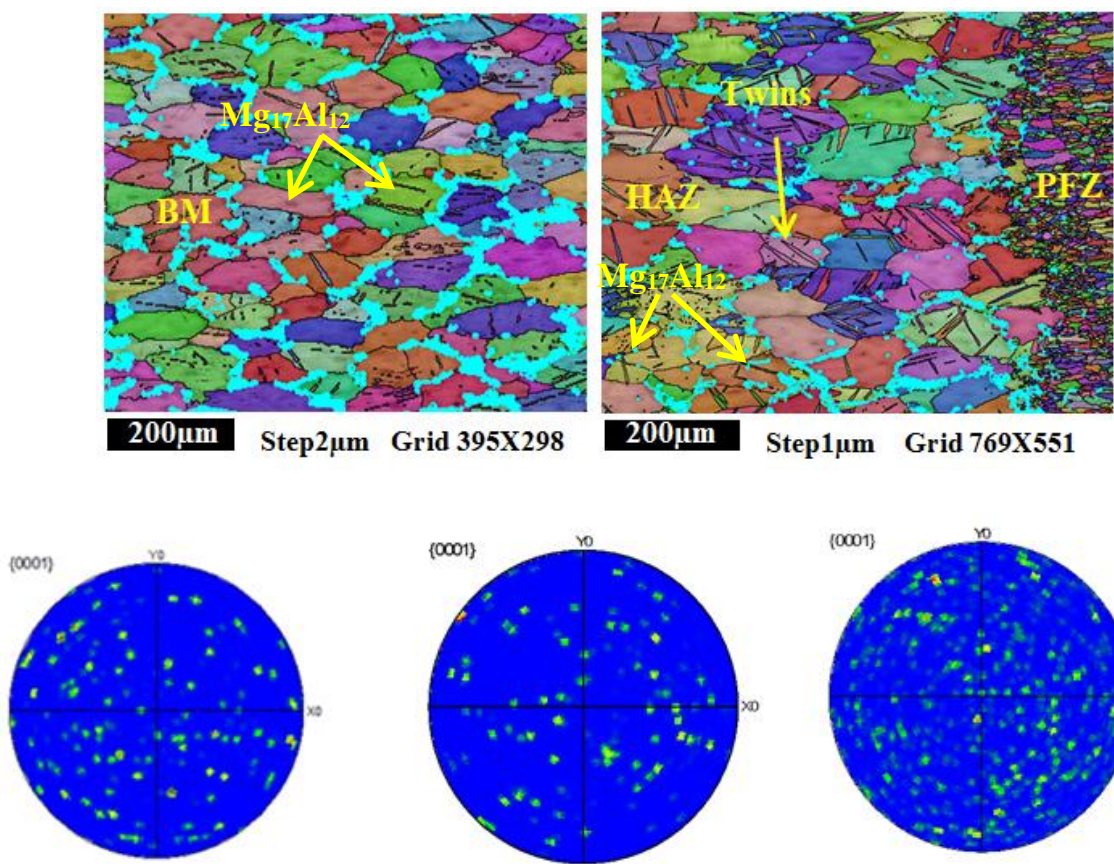

$\mathrm{BM}$

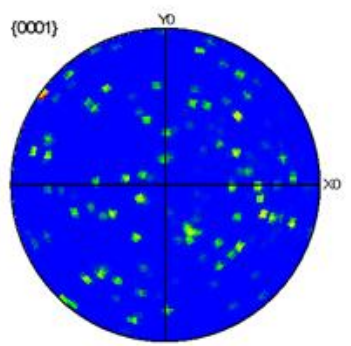

HAZ

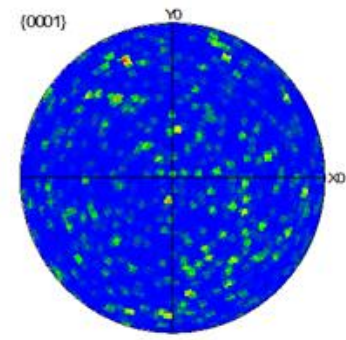

PFZ

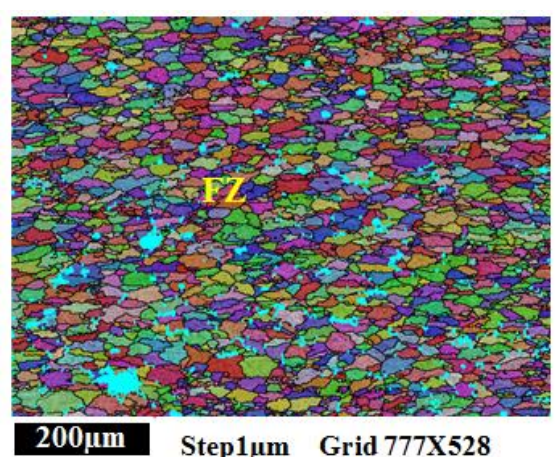

Step1 $\mu \mathrm{m} \quad$ Grid 777X528

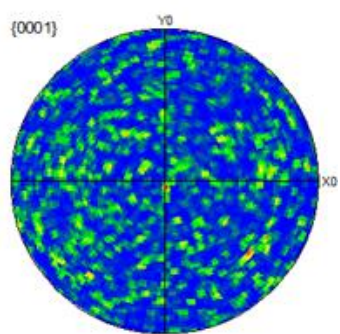

FZ

Fig.11: EBSD Analysis (a) EBSD maps and (b) pole figures of BM, HAZ, PFZ and FZ

On Fig.11b are represented the polar figures of the different areas of the weld, i.e. the stereographic projection of the crystallographic orientation along the basal plane (0001). No marked texture was observed along the basal plane (0001): the points are randomly distributed. However, it indicates that the $\mathrm{FZ}$ is a fine grained structure and the HAZ is a coarse grain microstructure. The grain size in the FZ is between $3 \mu \mathrm{m}$ to $35 \mu \mathrm{m}$, in the HAZ is $10 \mu \mathrm{m}$ to $187 \mu \mathrm{m}$, and in the BM is $10 \mu \mathrm{m}$ to $122 \mu \mathrm{m}$. In HAZ we can observe that, for the AM60B magnesium alloy, the only microstructure change in this zone is the liquefaction of the grain boundary bordering the molten region.

The phases present in the different areas of the weld are shown in Fig. 12 representing the X-ray diffraction patterns. In the FZ the most intense peak is the one corresponding to the (101) plane of the phase $\alpha \mathrm{Mg}$. The same result can be found in the BM. This peak is less intense in the HAZ. The same applies to the plans (102) (103). This result can be attributed to an effect of grain size. Barbagallo et al. [31] obtained the same peak intensity variations except that it was attributed to a different thermal state than that obtained during laser welding. The measurement of full width at half maximum (FWHM) of (101) $\alpha$-Mg plan increased in FZ suggesting that its grain size reduced, according to the Scherrer equation [32-33]. The result is shown in Fig.13. Comparing with the observation made by EBSD, this result confirms the effect of the refinement of the structure in the melted zone. 


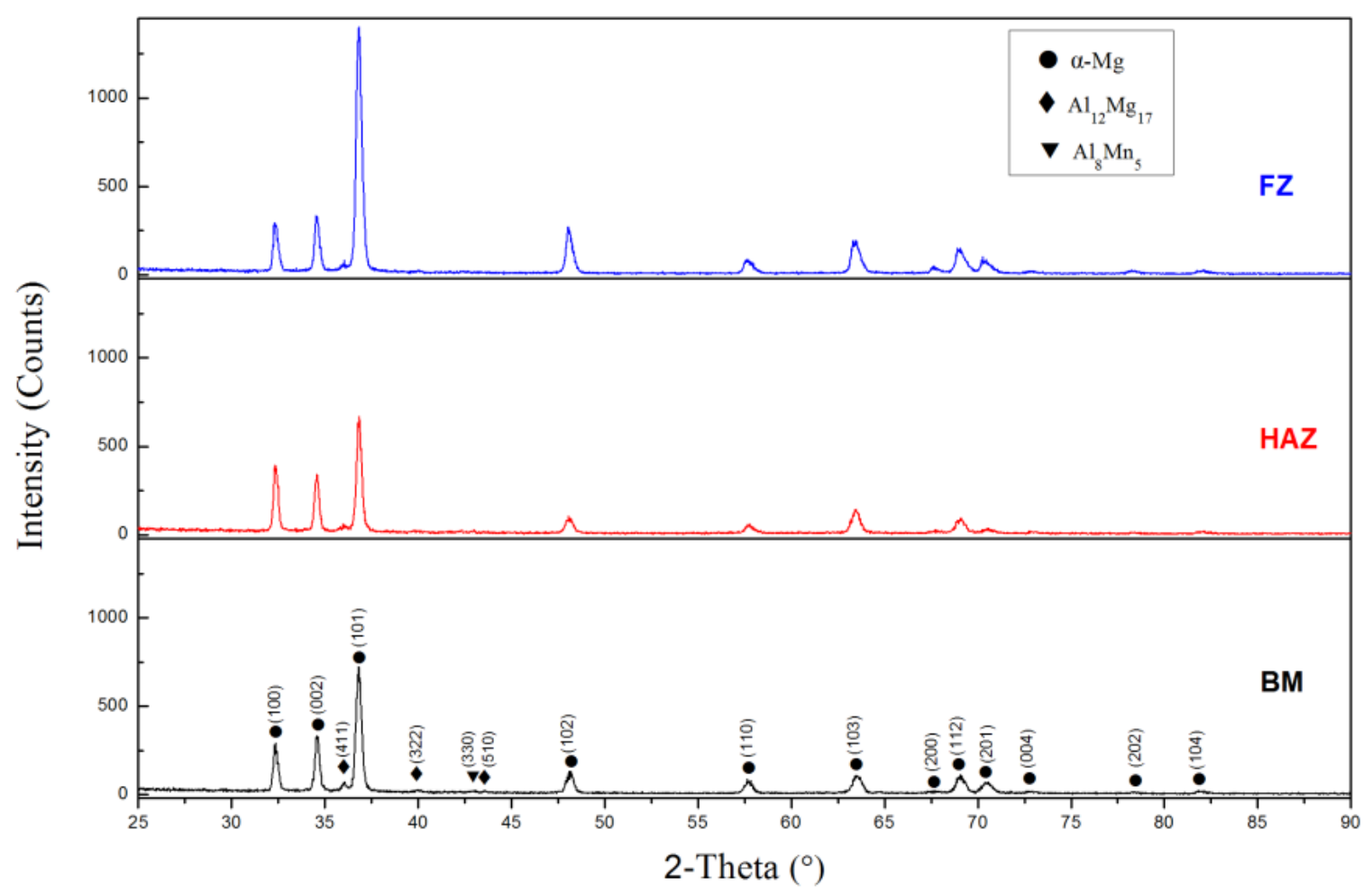

Fig.12: X-ray diffraction pattern of FZ, HAZ and MB

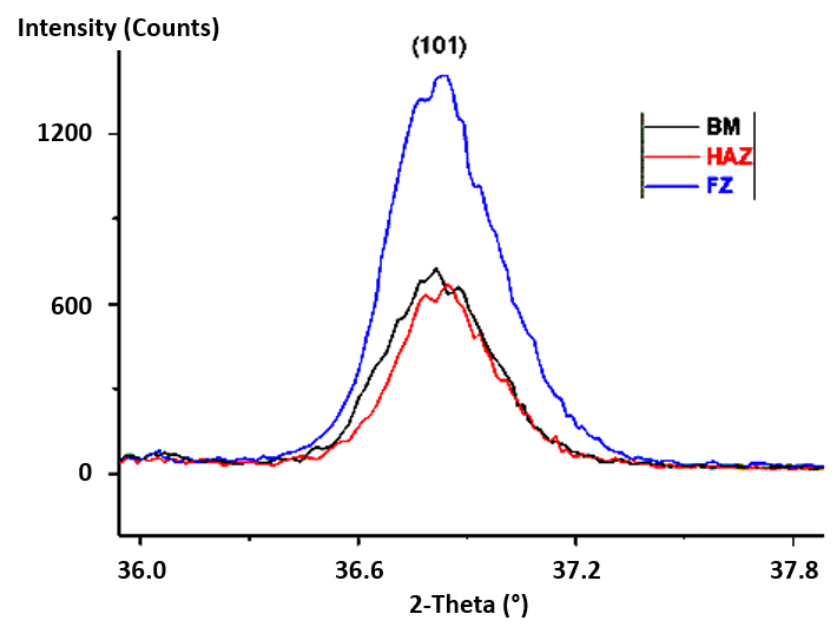

Fig.13: FWHM measurement for (101) $\alpha$-Mg plan for different zones

Moreover, in Fig.12, the peaks of the $\mathrm{Mg}_{17} \mathrm{Al}_{12}$ and $\mathrm{Al}_{8} \mathrm{Mn}_{5}$ phases are not intense due to their small size and volume fraction. Only the $\alpha-\mathrm{Mg}$ phase diffracted. Their presence on the diffractogram is limited to the planes (322) and (510) for the $\mathrm{Mg}_{17} \mathrm{Al}_{12}$ and the plane (330) for the $\mathrm{Al}_{8} \mathrm{Mn}_{5}$. EDS mapping shown in Fig. 14 better evidence the presence of precipitates $\mathrm{Mg}_{17} \mathrm{Al}_{12}$ and $\mathrm{Al}_{8} \mathrm{Mn}_{5}$. The yellow rectangle is the original image of the zone to be analyze. The red square on the mapping shows that this phase is rich in $\mathrm{Mg}$ element and $\mathrm{Al}$ (Fig.14b,c) whereas Mn does not present (Fig.14d). This seems indicate the presence of the $\mathrm{Mg}_{17} \mathrm{Al}_{12}$ phase. Similarly, the presence of $\mathrm{Mn}$ and $\mathrm{Al}$ (Fig.14c,d) on the stick-shaped part, whereas Fig. 14b shows an impoverishes part in $\mathrm{Mg}$, seems indicate the existence of $\mathrm{Al}_{8} \mathrm{Mn}_{5}$ intermetallic phase. 


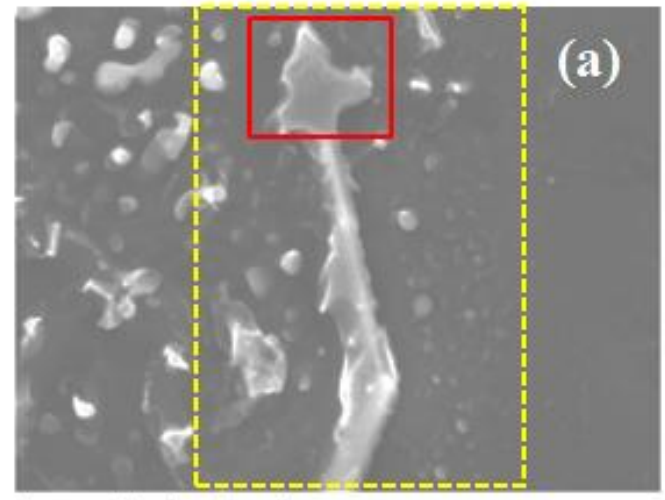

Image électronique 1

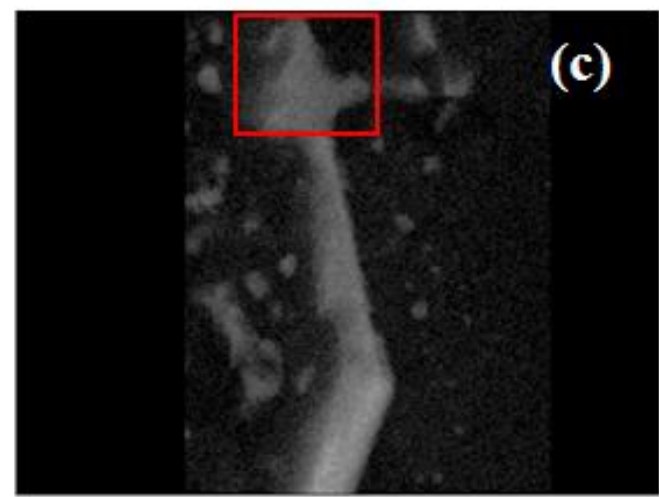

Al Ka1

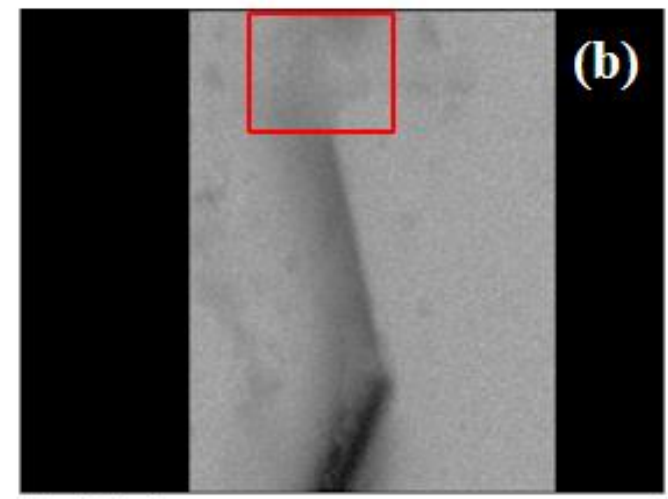

Mg Ka1_2

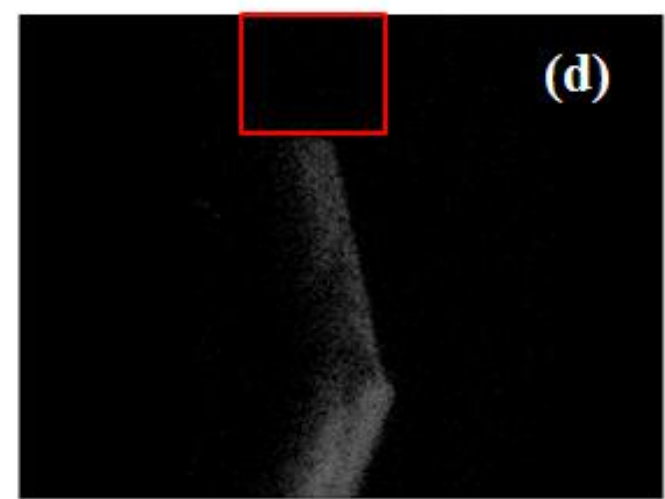

Mn Ka1

Fig.14: EDS mapping in FZ and PFZ (a) original SEM microstructure, (b) Mg element, (c) Al element,

(d) Mn element.

\subsection{Mechanical characterization}

Vickers microhardness profiles are carried out for welded samples obtained with optimized process parameters (Fig 16). It can be observed that microhardness values slightly increase on the fusion zone. This result is consistent with micro hardness measurement after $\mathrm{CO} 2$ and Nd:YAG laser welding of others die-cast magnesium-based alloys [7]. This hardness increase can be attributed to the refining of grains (Hall-Petch effect) in fusion zone and higher volume fraction of intermetallics such as $\mathrm{Mg}_{17} \mathrm{Al}_{12}$. The same result was observed by Shen et al. [34]. This result is consistent with previous microstructural observations (EBSD, XRD) which all show a strong decrease in grain size in the melting zone and the presence of the $\mathrm{Mg}_{17} \mathrm{Al}_{12}$ phase, uniformly distributed.

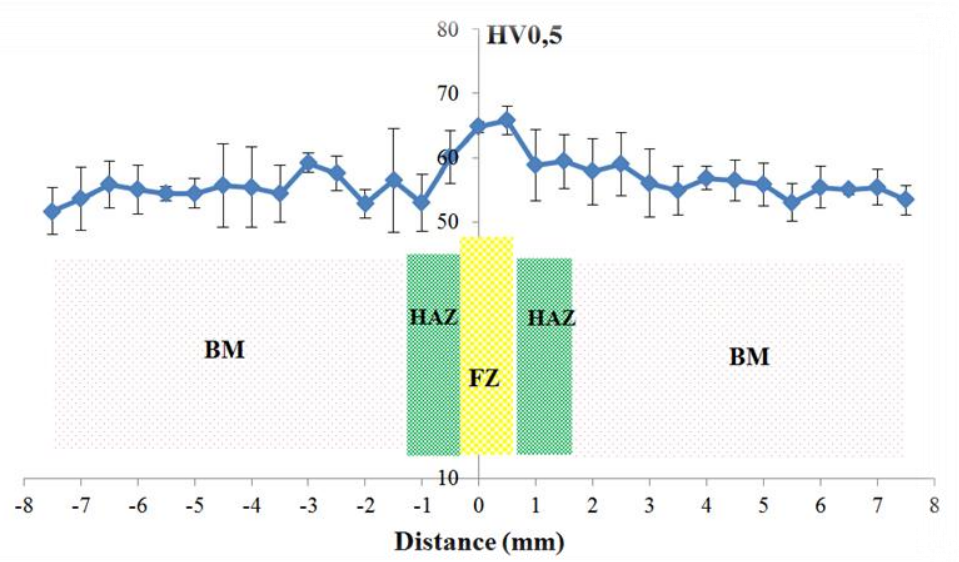

Fig.16: Microhardness profile evolution 
For the tensile tests, Fig. 17 shows the typical nominal stress and the tensile curve of the nominal strain at room temperature. All these test specimens were made on optimized welds. For specimens T3 and T7, the weld bead was polished before the tensile test.

For the BM, ultimate tensile strength (UTS) and elongation-to-failure (A\%) were $252 \mathrm{MPa}$ and $14 \%$, respectively. The values of these two parameters are variable. These values may vary slightly between two test specimens. The presence of defects in the material or the positioning of the test specimens in the tensile tester are the cause of these variations. The average values collected on the welded specimens are $247 \mathrm{MPa}$ and $14 \%$ that is very close to the values obtained for BM. In most of the tests, fractures of the welded samples occurred beyond the fusion zone. Table 6 shows the results of the tensile tests and gives the joint efficiency (weld joint UTS/base metal) as defined by Shen et al. [34]. The fall in UTS and A\% of the T8 and T9 samples can be explained by taking the test samples from an area at the end of the weld path.

In a few cases where fracture occurs in the melting zone, the dominant factor is the presence of porosities in this area (Fig.18). The SEM micrographs illustrate the presence of porosity on the FZ and PFZ in which two types of porosities are formed: spherical porosity and shrinkage porosity. Fig.18c represent a fractography of the broken $\mathrm{T} 2$ tensile specimen in the FZ where we find a large number of spherical porosities that is the cause of the $17 \%$ decrease in the UTS compared to the BM value. These porosities occur during the solidification of the melted laser zone due to a very high rate solidification and are responsible for the reduction of mechanical properties [35].

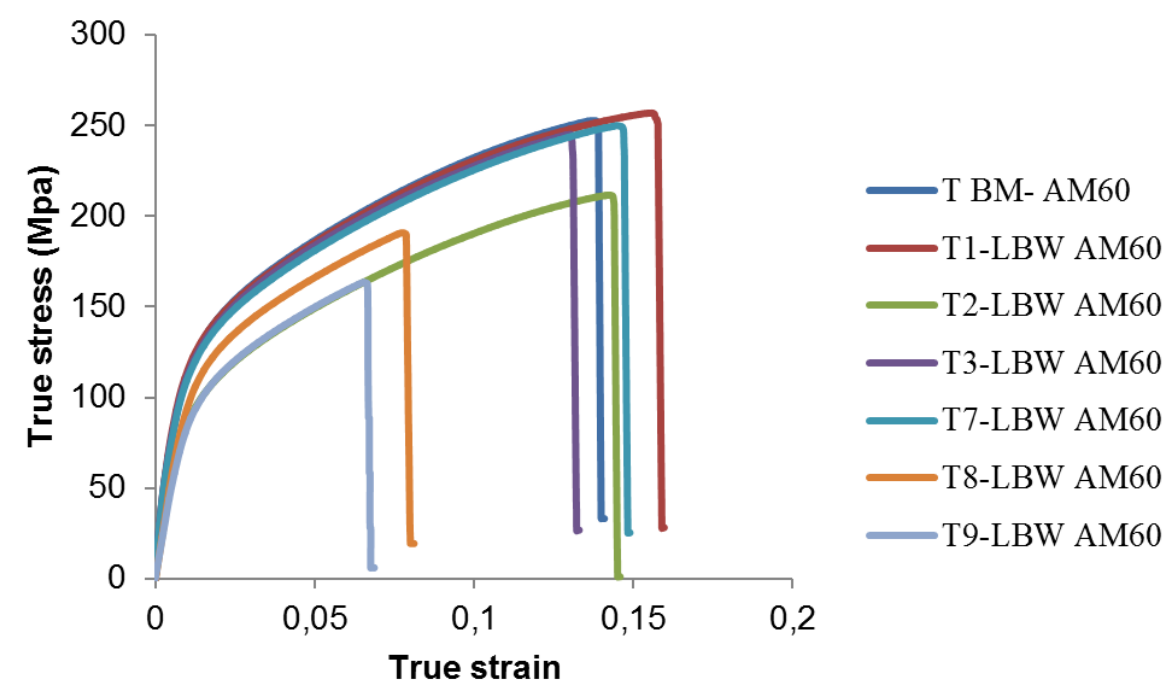

Fig.17: Tensile curves superposition of welded specimens and base metal.

Table 6. Resume of tensile test properties

\begin{tabular}{|c|c|c|c|c|c|c|}
\hline AM60 & Condition & $\begin{array}{c}\text { UTS } \\
(\mathrm{MPa})\end{array}$ & $\begin{array}{c}\text { Elongation } \\
\mathrm{A}(\%)\end{array}$ & $\begin{array}{c}\text { Rupture } \\
\text { zone }\end{array}$ & $\mathrm{UTS}_{(\mathrm{W})} / \mathrm{UTS}_{(\mathrm{BM})}$ & $\mathrm{A}_{(\mathrm{W})} / \mathrm{A}_{(\mathrm{BM})}$ \\
\hline $\mathrm{T}$ & Unwelded & 252 & 14 & $/$ & $/$ & $/$ \\
\hline T1 & Welded & 256 & 15 & BM & 1.015 & 1.07 \\
\hline T2 & Welded & 211 & 14 & FZ & 0.83 & 1 \\
\hline T8 & Welded & 191 & 8 & FZ & 0.75 & 0.57 \\
\hline T9 & Welded & 163 & 7 & FZ & 0.64 & 0.5 \\
\hline T3 & Welded, polished & 245 & 13 & BM & 0.97 & 0.93 \\
\hline T7 & Welded, polished & 250 & 14 & BM & 0.99 & 1 \\
\hline
\end{tabular}

$* \mathrm{UTS}_{(\mathrm{W})}$ Ultimate tensile strength of weld.

*UTS $(\mathrm{BM})$ Ultimate tensile strength of BM

$* \mathrm{~A}_{(\mathrm{w})}$ Elongation of weld specimen

*A(BM) Elongation of BM specimen 

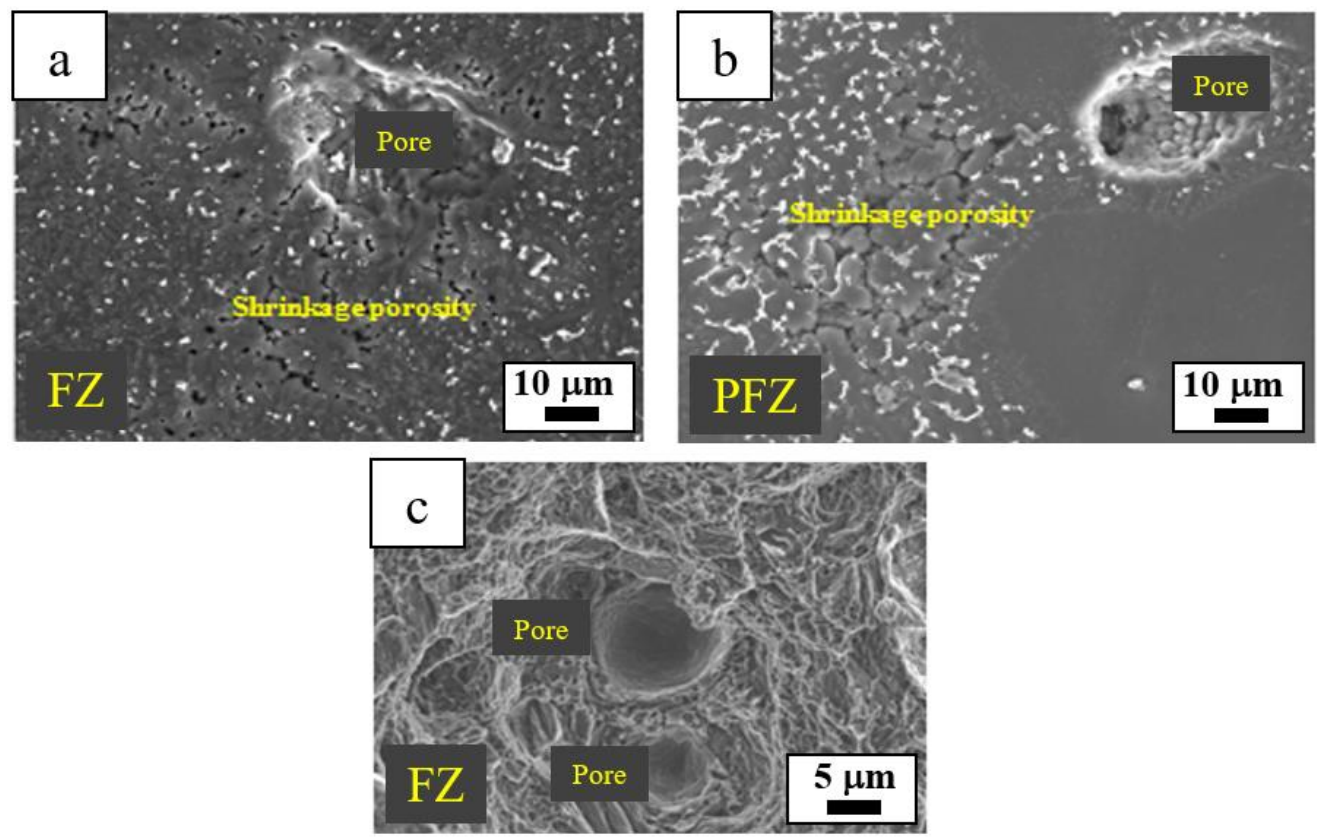

Fig.18: SEM microstructures of porosities morphologies: (a, b) shrinkage porosity and pore; (c) pores in fractography of T2 laser welded in FZ

\section{Conclusions}

AM60B magnesium-based alloy can be successfully welded with a focused Yb:YAG Laser beam. Based on the experimental results obtained in this work, the most important conclusions are summarized below.

1) In operating weldability, the operating parameters of power of $2 \mathrm{~kW}$ and variable speeds from 2 $\mathrm{m} / \mathrm{min}$ to $3.5 \mathrm{~m} / \mathrm{min}$ make it possible to obtain penetrating welds meeting the normative quality criteria.

2) In metallurgical weldability, the microstructure changes after laser beam welding are detected: a fine dendritic microstructure is observed in FZ and a reduced size of HAZ is obtained. A correlation between the results of EBSD and XRD analyses makes it possible to affirm the majority presence of the $\alpha-\mathrm{Mg}$ phase in the FZ. SEM observation and EDS mapping show that the $\mathrm{Mg}_{17} \mathrm{Al}_{12}$ intermetallic phase present only at the grain boundaries of the $\mathrm{BM}$ is distributed much more uniformly and finely in the HAZ and PFZ.

3) EBSD analysis shows a decrease in grain size in the melting zone and increase in grain size in the HAZ compared to the BM. Thermal twinnings appears in HAZ after laser welding. This phenomenon is then more important than in the BM.

4) The mechanical properties after welding are little affected by the joining process: there is a moderate hardness increase attributed to a refined microstructure (decreased grain size and distribution of the phase $\mathrm{Mg}_{17} \mathrm{Al}_{12}$ ), and a slight decrease of tensile properties due to the presence of small-sized pores in the melted zone.

\section{Acknowledgements}

The financial and technical supports of the Research Centre in Industrial Technologies (CRTI) and MSMP Laboratory of Arts \& Métiers ParisTech are greatly acknowledged. Great recognition towards Miss Corinne Dupy from the PIMM laboratory and Mr Jean-François Mathieu from MSMP laboratory for their practical contribution in laser welding technique. 


\section{References}

[1] W.A. Monteiro, S.J. Buso and L.V. da Silva. Application of Magnesium Alloys in Transport, New Features on Magnesium Alloys, W.A. Monteiro ed., InTech (2012), 161-174

[2] M.K. Kulekci, Magnesium and its alloys applications in automotive industry. Int J Adv Manuf Technol, 39 (2008), 851-865.

[3] G. Padmanaban, V. Balasubramanian, Influences of pulsed current parameters on mechanical and metallurgical properties of gas tungsten arc welded AZ31B magnesium alloy, V. Met. Mater. Int., 17, No. 4 (2011), 679-687

[4] G. Song and P. Wang, Pulsed MIG welding of AZ31B magnesium alloy, Materials Science and Technology, 27:2 (2011), 518-524

[5] Xu. Shen, G. Ma and P. Chen, Effect of welding process parameters on hybrid GMAW-GTAW welding process of AZ31B magnesium alloy. Int J Adv Manuf Technol, 94 (2018), 2811.

[6] W. Wang, D. Deng, Z. Mao et al., Influence of tool rotation rates on temperature profiles and mechanical properties of friction stir welded AZ31magnesium alloy. Int J Adv Manuf Technol, 88 (2017), 2191.

[7] X. Cao, M. Jahazi, J. P. Immarigeon, et al., A review of laser welding techniques for magnesium alloys, Journal of Materials Processing Technology, 171 (2006), 288.

[8] A. Belhadj, J.E. Masse, L. Barrallier et al., $\mathrm{CO}_{2}$ laser beam welding of AM60 magnesium-based alloy. Journal of Laser Applications, 22:2 (2010), 56-61.

[9] M. Wahba, M. Mizutani, Y. Kawahito et al., Laser welding of die-cast AZ91D magnesium alloy, Material \& Design, 33 (2012), 69-576.

[10] R.S. Coelho, A. Kostka, H. Pinto et al., Microstructure and mechanical properties of magnesium alloy AZ31B laser beam welds, Materials Science and Engineering: A, 485:1-2 (2008), 20-30.

[11] H.Y. Wang and Z.J. Li, Investigation of laser beam welding process of AZ61 magnesium-based alloy, Acta Metallurgica Sinica (English Letters), 18:4 (2006), 287-294.

[12] G. Padmanaban and V. Balasubramanian, Effects of laser beam welding parameters on mechanical properties and microstructure of AZ31B magnesium alloy, Transactions of Nonferrous Metals Society of China, 21:9 (2011), 1917-1924.

[13] Y. Quan, Z. Chen, X. Gong et al., $\mathrm{CO}_{2}$ laser beam welding of dissimilar magnesium-based alloys, Materials Science and Engineering: A, 496:1-2 (2008), 45-51.

[14] C.M. Lin, H.L. Tsai, C.L. Lee et al., Evolution of microstructures and properties of magnesium alloy weldments produced with $\mathrm{CO}_{2}$ laser process, Materials Science and Engineering: A, 548 (2012), 12-18.

[15] Z. Xiaobin and C. Zhanyi, Effects of pulse shaping on Nd:YAG laser spot welds in an AZ31 magnesium alloy, Optics and Lasers in Engineering, 119 (2019), 1-8.

[16] F. Caiazzo, V. Alfieri, F. Cardaropoli, et al., Butt autogenous laser welding of AA2024 aluminum alloy thin sheets with a Yb:YAG disk laser. Int J Adv Manuf Technol, 67 (2013), 2157-2169

[17] B. Chang, J. Blackburn, C. Allen et al., Studies on the spatter behaviour when welding AA5083 with a Yb-fibre laser. Int J Adv Manuf Technol, 84 (2016), 1769 
[18] S.T. Auwal, S. Ramesh, F. Yusof et al., A review on laser beam welding of titanium alloys. Int J Adv Manuf Technol, 97 (2018), 1071-1098

[19] N.V. Ravi Kumar, J. J. Blandin and M. Suéry, Effect of thermomechanical treatments on the microstructure of AZ91 alloy. Magnesium Alloys and their Applications. K. U. Kainer ed. (2006), 161167

[20] A. Khosravani , D.T. Fullwood , B.L. Adams et al., Nucleation and propagation of $\{10-12\}$ twins in AZ31 magnesium alloy. Acta Materialia, 100 (2015), 202-214.

[21] NF L06-395 standard, february 2010, Aerospace series - Weldments and brazements for aerospace structures - Joints of metallic materials by laser beam welding - Quality of weldments - Industrie aérospatiale

[22] P. Asadi, K. Kazemi-Choobi and A. Elhami, Welding of magnesium alloys, Welding of Magnesium Alloys, New Features on Magnesium Alloys, W.A. Monteiro ed., InTech (2012), 121-158

[23] T. Zhu, Z.W. Chen and W. Gao, Dissolution of Eutectic beta-Mg17Al12 Phase in Magnesium AZ91 Cast Alloy at Temperatures Close to Eutectic Temperature, Journal of Materials Engineering and Performance, 19 (2010), 860-867.

[24] V.Y. Gertsman, J. Li, S. Xu et al., Microstructure and Second-Phase Particles in Low- and HighPressure Die-Cast Magnesium Alloy AM50, Metall and Mat Trans A, 36 (2005), 1989-1997

[25] A. Kiełbus, Precipitate processes in Mg-5Al magnesium alloy, Solid State Phenomena, 191 (2012), $131-136$

[26] A.J. Gesing, J.H. Sokolowsk, P.C. Marchwica et al., Cooling curve and microchemical phase analysis of rapidly quenched magnesium AM60B and AE44 alloys, Journal of Achievements in Materials and Manufacturing Engineering, 58 (2013), 59-73

[27] F. Czerwinski, Near-liquidus molding of $\mathrm{Mg}-\mathrm{Al}$ and $\mathrm{Mg}-\mathrm{Al}-\mathrm{Zn}$ alloys, Acta Materialia, 53 (2005), 1973-1984

[28] A. Kiełbus, T. Rzychoń and R. Cibis, Microstructure of AM50 die casting magnesium alloy, Journal of Achievements in Materials and Manufacturing Engineering, 18 (2006), 135-138

[29] L.Yu, K. Nakata, N. Yamamoto et al., Texture and its effect on mechanical properties in fiber laser weld of a fine-grained Mg alloy, Materials letters, 63 (2009), 870-872

[30] M.R. Barnett, Twinning and the ductility of magnesium alloys, Materials Science and Engineering A, 464 (2007), 1-7

[31] S. Barbagallo, H.I. Laukli, O. Lohne et al., Divorced eutectic in a HPDC magnesium-aluminum alloy, Journal of Alloys and Compounds, 378 (2004), 226-232

[32] V. Uvarov and I. Popov, Metrological characterization of X-ray diffraction methods at different acquisition geometries for determination of crystallite size in nano-scale materials, Materials Characterization, 85 (2013), 111-123

[33] H. Zhang, K. Chong, G. Xiao et al., TIG cladding in-situ nano vanadium carbide reinforced Fe-based ultra-fine grain layers under water cooling condition, Surf Coat Technol, 352 (2018), 222-230 
[34] J. Shen, L. Wen, Y. Li et al., Effects of welding speed on the microstructure and mechanical properties of laser welded AZ61 magnesium alloy joints, Materials Science and Engineering A, 578 (2013), 303-309

[35] E. He, J. Liu, J. Lee et al., Effect of porosities on tensile properties of laser-welded Al-Li alloy: an experimental and modelling study, Int J Adv Manuf Technol, 95(2018), 659-671 